\title{
Algunas formas de la racionalidad. El problema educativo
}

TEÓFILO RODRÍGUEZ NEIRA

Universidad de Oviedo

\begin{abstract}
SUMMARY.-Rationality manifests itself in different forms and rests on different principles, forms and principles which are irreducible among themselves. Each form tende to eliminate and absorb the others. In addition the forms carry within themselves exegetical and educational models. But if education is to be as fully complete as possible it cannot allow itself to be reduced. So the different forms of rationality state a fundamental educational problem: that of the specific relationship education mantains with each of them and that of the accomplishment which is necessary to establish among themselves.
\end{abstract}

«Lo que hay que hacer es analizar racionalidades específicas más que invocar sin cesar los procesos de la racionalización en general».

(FOUCAULT: 1986, 28).

Las cuestiones referidas a la racionalidad, a las formas que es capaz de adoptar, a sus implicaciones en todos los ámbitos de la existencia, a sus repercusiones en la organización política y social, en la producción, en el orden tecnológico, científico y cultural, constituyen un campo que está sometido a una profunda revisión y a un extenso análisis. Baste mencionar la difusión y el uso educativo que las obras de Habermas dedicadas a estos problemas están adquiriendo en la actualidad. Theorie des Kommunikativen Handelns (Band 1: Handlungsrationalität und gesellschaftliche Rationalisierung; Band 2: Zur Kritik der funktionalistischen Vernunft); Moralbewusstein und Kommunikatives Handeln; Zur Logik der Sozialwissenschaften; y otros muchos escritos de obligada referencia en los debates académicos, están introduciendo perspectivas que han llegado a una nueva orientación incluso de los planteamientos didácticos.

La temática que aquí nos ocupa, por otra parte, independientemente de la actualidad que algunos planteamientos críticos puedan tener, ha nacido con la civilización misma de Occidente. Y sustraerse a su estudio y comprensión es renunciar a la dimensión básica de nuestro devenir histórico y al soporte esencial de la práctica educativa. 
Naturalmente, no se trata aquí de desarrollar internamente todas las concepciones, ni de discutir las distintas alternativas minuciosamente y al por menor, ni de presentar una nueva visión de estos procesos. Sólo se intenta una primera aproximación e inicial toma de contacto describiendo algunos de los supuestos e implicaciones de algunas formas determinadas de la racionalidad. Se parte de la hipótesis según la cual estas formas son diversas e irreductibles entre sí. En consecuencia, habrá que considerarlas separadamente, ver quiénes son sus defensores y promotores y hasta dónde llegan en sus pretensiones más radicales.

No es una cuestión sencilla analizar los modos a través de los cuales se alcanza una racionalización y las repercusiones que estas conquistas, que estos logros, en la medida en que realmente se consigan, tienen sobre los mecanismos de interacción y sobre los mismos sujetos que en ellos intervienen.

Lo que se descubra, lo que acontezca, dependerá de lo que se entienda por razón y del uso que de ella efectivamente se haga. Porque no se trata de un término unívoco, ni de una única línea de objetivación, ni siquiera de un prototipo de racionalización frente a otros, sino de una serie de niveles que se interconectan entre sí y que desencadenan un sentido que delimita etapas históricas y que configura modalidades de la cultura bastante diferentes unas de otras y hasta, a veces, contrapuestas.

La escuela sufrirá directamente cualquiera de las modalidades racionales, pues ella, constituye el ámbito privilegiado de sus manifestaciones y propagación.

\section{LA RAZÓN: GUÍA DEL PENSAMIENTO Y DE LA ACCIÓN}

Una de las primeras acepciones que encontramos es aquella que nos presenta la razón como conductora de la vida del hombre en el mundo tanto desde el punto de vista ético como cognitivo. No sólo indica lo que debe hacerse, sino que hace posible la indagación y el descubrimiento en términos de verdad, o simple investigación. La razón es la «facultad» o capacidad que distingue al hombre de los animales.

Por una parte le permite al hombre superar sus instintos y apetitos inferiores, y, por otra, liberarse de prejuicios, leyendas, mitos, convicciones gratuitas, opiniones infundadas y de falsas apariencias. Estos dos sentidos aparecen íntimamente unidos desde los orígenes de nuestras formas de pensamiento.

Parménides representa uno de los autores en los que de una manera más explícita se formula este carácter de la razón:

«Te invito a que consideres todo esto, pero, a la vez, quiero prevenirte acerca de esta vía de la búsqueda y en cuanto a aquella otra por la que se lanzan los mortales ayunos de saber, que marchan errantes en todas direcciones, cual si de monstruos bicéfalos se tratase. Porque es la perplejidad la que en el pecho de estos dirige su espíritu vacilante. $\mathrm{Y}$ así se ven llevados de aquí para allá, sordos, ciegos y llenos de asombro, como turba indecisa... en un caminar en pos de todo que es un andar y un desandar continuo... Pero tú, no obstante, aleja tu pensamiento de esta vía y no te dejes llevar sobre ella por la fuerza rutinaria de la costumbre, ni manejando tus ojos irreflexivamente, ni tus oídos que recogen todos los ecos, ni acaso tu lengua; juzga, por el contrario, con razones que admitan múltiples pruebas, como las que yo te he mostrado» (Diels, I: 30-37). 
Estas vías, estos caminos de indagación que Parménides describe, dejando a un lado las muchas interpretaciones a que han dado lugar, abren la realidad de dos mundos enfrentados, dos mundos que recogen la existencia humana. Uno de ellos comprende el reino de la costumbre, de las opiniones imperantes, de los hábitos colectivos de conducta, y otro está formado por los saberes fundados, por razones apoyadas en múltiples pruebas. Este último es el que conduce a la verdad, al descubrimiento de la realidad y al conocimiento del ser.

Jaeger, que encuentra una tercera vía en el planteamiento de Parménides y que lo interpreta desde la perspectiva de la dicotomía entre religión y filosofía, reconoce, sin embargo, la preeminencia que otorga al pensamiento racional en cuanto nuevo orden de la justicia y de la verdad: «Entre las fuentes de las humanas experiencias que cooperan a transformar el tradicional concepto mítico de lo Divino, fue la investigación racional de la realidad una de las más importantes; y así como la misma indagación religiosa había estimulado el apetito de conocer, de igual manera la especulación filosófica con que los griegos aspiraron constantemente a adueñarse de la totalidad de la existencia llevó a cabo una función verdaderamente religiosa, dando origen a una peculiar religión del intelecto que refleja en su estructura el cambio de relaciones entre la razón y el sentimiento que nos hace frente en aquel nuevo tipo intelectual, en el filósofo» (Jaeger, 1977: 94).

El Poema de Parménides admite varias lecturas distintas de las de Jaeger. También diferentes de las referencias al impacto social de Farrington o a los análisis metafísicos, ontológicos y noéticos que de ordinario se han practicado en torno a su figura y su significado.

Si separamos los distintos reinos ante los que aparece la razón y el pensamiento -medida, criterio y pauta del ser, una y la misma cosa con el ser-, se pueden diferenciar, siguiendo el propio escrito de Parménides, varias grandes líneas del discurrir humano. (Beaufret, 1955: 78).

1. Aquella que está fijada por las opiniones subjetivas, condicionadas por el tumulto de los instintos, deseos, apetencias y necesidades elementales que brotan de las raíces más profundas de la vida. Son las inclinaciones emergentes las que traen de acá para allá al individuo carente de razón y pensamiento.

2. Las pautas, normas, creencias y convicciones que regulan el comportamiento y que, ya sean de origen político o de origen religioso, indican los límites de lo que está bien o mal, de lo que puede pensarse o no, de lo que está permitido o vedado, de lo que es o no es valioso colectiva y personalmente.

3. El mundo formado por «las apariencias», por el fluir sensible y perceptivo, por el impacto de los estímulos inmediatos, por lo que es y no es al mismo tiempo, por lo que es no ser. Es el mundo de la turba indecisa, que van en pos de todo, que andan y desandan el mismo camino constantemente.

4. Existe, además, la multitud de las mezclas, los que circulan por una u otra vía sin criterio ni reflexión, los que incluso giran durante un momento la cabeza hacia la claridad del pensamiento pero tornan al compromiso del parecer colectivo o al imperativo de la regla común.

5. Finalmente, la vía por excelencia, la que debe reducir el resto de los caminos, la que llega hasta el interior de la luz, de la verdad y del ser, la vía de la razón y del pensar, 
la vía para la que «una y la misma cosa es el ser y el pensar» o para la que «la misma cosa existe para el pensar y para el ser». La fórmula diversifica de nuevo las interpretaciones. Pero una de sus implicaciones es que aquello que no existe no puede ser pensado y lo que no puede ser pensado no existe. Del mismo modo, quizá, supone que aquello que puede ser pensado existe y que lo que existe puede ser pensado. Las distintas fórmulas admiten que el recorrido de la razón abarca el ser, la verdad, y que aquella es comprendida por éste. La racionalidad reduce críticamente todas las otras vías y cualquier escisión en su proceso significa una caída que ha hecho de Parménides el pensador por excelencia de la unidad, de la necesidad y del imperio de la razón. En su cumplimiento no hay divisiones posibles. Lo que realmente establece Parménides es la legitimación, el dominio, la hegemonía de la racionalidad especulativa. A ella deberá reducirse cualquier otra forma de racionalidad. La academia y la escuela tendrán que ser, en última instancia, especulativas.

Nos hemos detenido en Parménides, no sólo porque marca un punto de partida que ya no va a poder ser olvidado por la civilización, sino porque representa la máxima unidad, unificación, de la racionalidad. Pero la frontera de lo que hoy ocurre con los procesos de la razón está determinada por la Ilustración y por el modelo que implantó. Es la propuesta de la Aufklärung la que está en el origen de la disgregación y separación actual. Entre Parménides y la Ilustración existen más de dos milenios de discusiones en las que las distintas alternativas están anticipadas. No obstante, la Ilustración es una de nuestras fronteras más próximas e ineludibles.

\section{LA RACIONALIDAD ILUSTRADA}

Un primer acercamiento sobre el que pueda darse un consenso bastante general, nos obliga a destacar, como postura básica de todos los pensadores ilustrados, la constante exaltación y defensa de la racionalidad científica como forma primordial de la existencia humana.

1. El ejercicio del entendimiento y de la razón expresan la verdadera madurez del hombre. Su uso permite la conquista de la autonomía y el ingreso en la mayoría de edad de la humanidad. «La Ilustración, decía Kant, es la salida del hombre de su autoculpable minoría de edad. La minoría de edad significa la incapacidad de servirse de su propio entendimiento sin la guía de otro. Uno mismo es culpable de esta minoría de edad cuando la causa de ella no reside en la carencia de entendimiento, sino en la falta de decisión y valor para servirse por sí mismo de él sin la guía de otro. Sapere aude!: Ten el valor de servirte de tu propio entendimiento!, he aquí el lema de la Ilustración» (Kant, 1988: 9).

2. La razón es el principio y fundamento de la crítica. Por eso requiere la práctica de la libertad frente a cualquier orden establecido o por establecer. «Una época no puede obligarse ni juramentarse para colocar a la siguiente en una situación tal que le sea imposible ampliar sus conocimientos (sobre todo los muy urgentes), depurarlos de errores y, en general, avanzar en la Ilustración. Sería un crimen contra la naturaleza humana, cuyo destino primordial consiste, justamente, en ese progresar. Por tanto la posteridad está plenamente justificada para rechazar aquellos acuerdos, aceptados de forma incompetente y ultrajante. La piedra de toque de todo lo que puede decidirse como ley para un 
pueblo reside en la siguiente pregunta: ¿podría un pueblo imponerse a sí mismo semejante ley? Esto sería posible si tuviese la esperanza de alcanzar, en corto y determinado tiempo, una ley mejor para introducir un nuevo orden, que, al mismo tiempo, dejara libre a todo ciudadano, especialmente a los sacerdotes, para, en cuanto doctos, hacer observaciones públicamente, es decir, por escrito, acerca de las deficiencias de dicho orden» (Kant, 1988: 14).

3. La razón es, por su capacidad para instaurar un orden, la única fuerza mediante la cual se puede renovar radicalmente el mundo humano.

4. Es la razón, por último, el tribunal de sí misma. No existe ninguna instancia, ninguna otra capacidad ni principio, ninguna autoridad extraña a ella misma, ante la que deba rendirse. Para no dejarse reducir por un saber aparente, la razón se ve forzada a la más difícil de sus tareas, a la de analizar el propio conocimiento. Este análisis lo lleva a cabo estableciendo un tribunal «que la asegure en sus pretensiones legítimas y que en cambio acabe con todas las arrogancias infundadas, y no por medio de afirmaciones arbitrarias, sino según sus eternas e inmutables leyes. Este tribunal no es otro que la Crítica de la razón pura misma». Esta razón pura «es una unidad tan perfecta, que si su principio fuera insuficiente para sólo una de las cuestiones que le son propuestas por su propia naturaleza, habría desde luego que desecharlo, porque entonces no sería adecuado para resolver, con completa seguridad, ninguna otra» (Kant, 1969: 7 y ss.).

Sin embargo, la contribución más importante de la Ilustración a la racionalidad social y sus implicaciones, no consiste simplemente en esa preeminencia de la razón y defensa del progreso -aunque se aplique a sus pretensiones la mediación del entendimiento-, sino en la incorporación entre el conocimiento y la realidad, entre el conocimiento y los fenómenos, las cosas, de un nuevo elemento, una nueva estrategia cognoscitiva y práctica. Ahora se recurre a los objetos, que no son cosas, ni representaciones puras, sino síntesis esenciales de todo hecho de conocimiento. Los objetos significan lo conocido, y son la superación de la subjetividad. Lo que existe al margen del objeto, los seres en sí, los entes independientes del hecho de conocimiento, nunca podrán ser entendidos. Los objetos «tienen que regirse, según la expresión kantiana, por nuestro conocimiento». El mundo objetivo es el mundo de la experiencia, un mundo ordenado por los «conceptos» del entendimiento. Es cierto que los datos fenoménicos son necesarios para corregir la tendencia de la razón hacia lo incondicionado, tendencia a ir más allá de toda experiencia posible, son necesarios para superar «las ilusiones transcendentales», pero los datos sensibles por sí mismos son ciegos y carentes de sentido. No hay, desde esta perspectiva, un orden objetivo que no sea un orden del conocimiento.

No obstante, el orden del conocimiento, cuyas posibilidades y límites tiene que instaurar la razón, es, en primer lugar, el orden del conocimiento científico. El establecimiento del ámbito científico, de lo que podríamos llamar la noosfera, garantiza su consistencia interna, su validez y los principios que fundamentan su autonomía.

Frente a este conocimiento, a la racionalidad científica, cuyo camino más seguro está representado por las matemáticas y la física, el conocimiento especulativo, pese a su milenaria implantación, únicamente ha producido contradicciones e ilusiones vanas. En esta racionalidad especulativa, que tan denodadamente proponía Parménides, «tropieza la razón continuamente, incluso cuando quiere conocer a priori (según pretende) aquellas leyes que la experiencia más ordinaria confirma. En ella hay que deshacer mil veces el 
camino, porque se encuentra que no conduce a donde se quiere; y en lo que se refiere a la unanimidad de sus partidarios, tan lejos está aún de ella, que más bien es un terreno que parece más bien destinado a que ellos ejerciten sus fuerzas en un torneo, en donde ningún campeón ha podido hacer la más mínima conquista y fundar sobre su victoria una duradera posesión. No hay, pues, duda alguna, de que su método, hasta aquí, ha sido un mero tanteo y, lo que es peor, un tanteo entre meros conceptos» (Kant, 1960: 24). La búsqueda de lo incondicionado, que era el objetivo de la razón especulativa, «no puede ser pensado sin contradicción» (Id., p. 29).

Todo el esfuerzo kantiano va encaminado a establecer, delimitar y caracterizar la razón tal y como se produce a través del «seguro camino de la ciencia». Es decir, Kant eleva la racionalidad científica a «paradigma» y modelo de la racionalidad. Este proceso se había iniciado desde muy atrás. Pero ahora, y el fenómeno se puede extender a toda la Ilustración, la racionalidad científica asume un papel hegemónico y preferente frente al cual el resto de las formas de racionalidad especulativa es desbaratada y reducida a una función crítica, o mejor, gnoseológica. Al mismo tiempo, se abre la vía para una racionalidad «práctica» independiente. Se consuma la escisión y división de las racionalidades. La unidad especulativa es un empeño imposible.

Cuando Moses Mendelssohn se propone analizar los términos: Ilustración, cultura, Educación, hace las siguientes aclaraciones: «Cuanto más se pone en armonía la situación social de un pueblo, por medio del arte y del trabajo con el destino humano, tanta más educación tiene ese pueblo.

La educación se descompone en cultura e ilustración. Aquella parece que atañe más a lo práctico: por un lado, a lo bueno, al refinamiento y belleza en la artesanía, artes y costumbres sociales (cultura objetiva); por otro lado, a la destreza, trabajo y habilidad en las primeras y a las tendencias, instintos y hábitos en las últimas (cultura subjetiva). Cuanto, estas cualidades, más se corresponden en un pueblo con el destino del hombre, tanta más cultura se atribuye a aquél, al igual que de un campo se dice que está tanto más cuidado y cultivado cuanto más está en situación, debido al trabajo humano, de producir cosas útiles para los hombres. La Ilustración, por el contrario, parece referirse más bien a lo teórico. Al conocimiento racional (objetivo) y habilidad (subjetiva) para reflexionar razonablemente sobre las cuestiones de la vida humana, en consecuencia con la importancia e influencia sobre el destino humano».

La Ilustración reúne el conocimiento racional (objetivo) y la habilidad (subjetiva) en una racionalidad reflexiva, de modo que ambas son aspectos de un mismo proceso. La Ilustración se adquiere «por medio de las ciencias, la cultura a través de su uso social. Gracias a aquella se vuelve más exacta para lo teórico», por ésta, «para lo práctico». «Las dos juntas proporcionan educación a un pueblo». Las ciencias son un momento de la objetividad de donde derivan el resto de las cualidades. En realidad, sobre la educación recae ahora una tensa dualidad cuyo equilibrio sería cada vez más inestable. Cultura e ilustración, teoría y práctica, conocimiento racional y habilidad subjetiva pueden tender a posiciones irreconciliables.

La Ilustración nos ha dejado en herencia el problema de las distintas formas de racionalidad a cuyo través el hombre comprende y maneja el mundo, comprende y maneja su existencia. Goldmann veía esta separación como un hecho trágico. Pero en nuestra época, en nuestra situación postilustrada, han aparecido nuevas formas de racionalidad cuyo 
impacto es peculiarmente visible en el orden social y en la desproporcionalidad pública desencadenada.

Las nuevas formas de racionalidad no se generan y se hacen visibles desde el reino de la especulación, ni desde el de la gnoseología o epistemología, ni desde el de la ciencia, sino que aparecen principalmente en el sistema de producción y repercuten directamente sobre la estructura social. El análisis, por lo tanto, cambia de realidad. Ahora tiene que centrarse en el propio orden social para perfilar y comprender lo que de hecho está ocurriendo, para entender la génesis y la naturaleza de las nuevas formas de la racionalidad y de los nuevos sistemas operativos.

\section{PROPORCIONALIDAD Y DESPROPORCIONALIDAD SOCIAL: LA RACIONALIDAD FUNCIONAL}

Podemos partir de un ejemplo sencillo que nos permita ir retrocediendo hasta el orden o el desorden social y las fuerzas en que se amparan, hasta la racionalidad en que se fundamentan y apoyan.

En una sociedad coinciden elementos no coetáneos, no pertenecientes a idéntica época histórica ni al mismo sistema de producción, sin que por ello surjan necesariamente desequilibrios significativos. A la manera como en una catedral se conjugan un muro románico, una columna gótica y un retablo barroco, sin que falte la armonía y la belleza de conjunto, puede ocurrir en toda sociedad, y de hecho así ha sucedido en otras épocas de la historia, que la confluencia de factores y materiales de distinta índole y procedencia no impliquen desarreglos o trastornos profundos. Pero hay momentos, no obstante, en que la concurrencia se hace insoportable y contradictoria. En estos casos se produce una falta «de proporcionalidad en el desarrollo de las capacidades y facultades humanas» y una «desproporcionalidad social». El desajuste puede adquirir tales dimensiones que la vida colectiva se haga problemática y la sociedad se incapacite para subsistir.

Esta perspectiva, como se sabe, ha sido planteada por Mannheim cuyos pasos nos permitirán observar los límites y condicionamientos de la racionalidad funcional.

«Tanto el hombre individual como los grandes grupos históricos pueden padecer, incluso sucumbir en ciertas circunstancias, cuando sus distintas capacidades se desarrollan de modo desigual, no acordes entre sí. Lo que nos ha confiado la Psicología infantil de que un joven puede desarrollarse espiritualmente con inaudita rapidez, mientras que sus juicios morales o sus cualidades de gusto permanecen en un plano infantil, es también posible en la vida de los grupos históricos. Si una tal desigualdad en el desarrollo total es peligrosa ya para el individuo, en el seno de una Sociedad tiene que conducir pronto o tarde a la catástrofe» (Mannheim, 1958: 26).

La distinción entre la proporcionalidad de las capacidades individuales y la proporcionalidad social nos lleva a otorgar a una de ellas la preeminencia sobre la otra. Ha habido momentos históricos en los que se asignó a la primera el papel de promotora frente a la segunda. Hoy tenemos que establecer la función condicionante de la segunda. La razón es fácilmente comprensible: La división del trabajo y la diversidad de las ocupaciones sociales son las que atribuyen al individuo el puesto social que le corresponde y el 
tipo de cualidades que debe desarrollar. Este hecho crea además las expectativas que permitirán surgir las élites en el campo del saber y en la toma de decisiones. La estructura social fomenta la participación e iniciativa de ciertos grupos y condena a otros a la pasividad. Esta distribución funcional adoptó en algunas sociedades la forma de castas. Unos acumulaban el saber y la capacidad de decidir mientras otros sólo podían asumir actividades de servicio y de obediencia. Podríamos afirmar, incluso, que gran parte de la estructuración social se montó sobre estas prácticas. «Hasta ahora, escribió Mannheim, todas las ordenaciones sociales pudieron permitirse hacer valer una desproporcionalidad en la distribución de la ratio y de las fuerzas sociales, porque precisamente descansaban en esa desproporcionalidad social de los elementos racionales y morales. Una sociedad dominada por un déspota -para citar un ejemplo extremo, en que puede observarse sin complicaciones el actuar de las fuerzas- consiste en que la máxima perspectiva e iniciativa necesaria para dominar la Sociedad se encuentran en el déspota, y los demás, los esclavos y subyugados, carecen de una visión sobre el todo y de iniciativas. Frente a esto, la novedad de la Sociedad moderna consiste en que no puede soportar de manera permanente las dos citadas formas de la desproporcionalidad: ni la falta general de proporcionalidad y moralidad en la dominación espiritual del total proceso, ni su desigual distribución social» (Id., 28).

Dos series de hechos apoyan esta afirmación, es decir, la tesis según la cual nuestra sociedad no soporta la desproporcionalidad racional ni la desproporcionalidad moral.

En primer lugar, desde la revolución industrial y la tecnologización de la vida, se ha instado de manera constante a la participación de capas cada vez más amplias de la sociedad. Ninguno de esos movimientos hubiese sido posible sin la intervención de individuos y grupos que hasta ellos sólo de una forma sumisa y receptiva estaban presentes en el escenario político. A este proceso de activación se le ha denominado «democratización fundamental de la sociedad».

En segundo lugar, en nuestra sociedad ha hecho acto de presencia otro fenómeno, que ha sido llamado fenómeno de la interdependencia. Los centros de actividad se relacionan y enlazan entre sí de una manera cada vez más estrecha y rígida. Cualquier núcleo de producción que se aisla y cierra corre serio peligro de extinción y desaparición. Las nuevas tecnologías crean una red mundial que distribuye la información, anticipa las necesidades, fomenta nuevas industrias y recorre el mercado depositando objetos cada vez más sofisticados y precisos.

El panorama actual de todas las sociedades avanzadas ofrece un parecido espectáculo: Todos los estamentos sociales luchan por una mayor participación en los acontecimientos comunitarios y estatales, por una mayor representación de los propios intereses. Si este acontecimiento no va acompañado de un desarrollo de la racionalidad y de la moral de la colectividad, de la promoción de canales de gestión e intervención, los individuos quedarán a merced de los poderosos, de los demagogos y del impacto de los medios de comunicación. Una democracia no subsiste sin un sistema cuyas reglas sean una progresiva racionalidad y eticidad de la conducta y de la convivencia. De todas maneras, los peligros que atentan contra esta ascensión son múltiples y complejos. Entre ellos, hay algunos que son claramente visibles:

$1^{\circ}$. La concentración y centralización de capitales. Las organizaciones que resumen en unas cuantas personas la gestión, la producción, la localización de las industrias y la 
clase de bienes que han de ser consumidos tienen en sus manos un instrumento poderoso de coerción y de control. El bienestar y la riqueza de poblaciones enteras pende de equipos que ni siquiera están localizados en las fronteras del país al que aquellas pertenecen. Los presupuestos de algunas de estas organizaciones son superiores al de muchos gobiernos y estados.

$2^{\circ}$. La monopolización de las posiciones de poder social, de los órganos de decisión. Los grupos ascendentes luchan por usufructuar y perpetuar los puestos dominantes.

$3^{\circ}$. Los medios de comunicación. Los creadores de opinión son conscientes de sus posibilidades. Disponer de ellos es disponer de la realidad misma. Un suceso no amparado por ellos es como si prácticamente no hubiese ocurrido.

$4^{\circ}$. La extensión de la racionalización exige la presencia de «profesionales especializados y ejercitados en la división del trabajo. De este modo cada vez se concentra más, por razones objetivas (valga la frase), la inteligencia social y capacidad de mando en las cabezas de unos pocos políticos, directores de la Economía, técnicos de la Administración y especialistas del Derecho.

$5^{\circ}$. De la mano de esta monopolización del saber viene la concentración del hacer en una burocracia más separada cada día de las demás capas sociales. Lo esencial en la diferencia entre las disposiciones individuales de la época liberal y la organización burocrática del presente y futuro próximo no es el grado de eficacia del rendimiento de trabajo, las formaciones de intereses y las ideas objetivas del fin. Lo decisivo es la formación de una capa burocrática, de tipo análogo a las clases, que a la larga se introduce, traspasando el ámbito de la Administración pública, en la esfera de la Economía y de la Cultura. Como fiel en la balanza entre los grupos contendientes de la Sociedad, o como aliada de ciertas capas, la burocracia tiende a constituirse a sí misma en unidad funcional y a asegurar el monopolio de su mando con todas las armas sociales útiles para la clausura de los grupos hasta hacer hereditario el cargo».

$6^{\circ}$. Todavía se menciona, y el hecho ha sido decisivo en la historia política de nuestro siglo, «la concentración de los medios militares de poder». El poder destructivo de las armas atómicas introduce un factor de terror que altera las posiciones clásicas. No exclusivamente por la amenaza latente o expresa de una destrucción universal que convierte a todos los habitantes de la tierra en sujetos potenciales de un holocausto general, sino por la concentración en unas pocas manos, comparado con el resto de la población, de las decisiones y ejecuciones que el mantenimiento y aplicación de un instrumento tan complejo supone. Industrias gigantescas, sistemas de almacenamiento y conservación, especialistas, técnicos y profesionales viven, prosperan y se comprometen a través de un mecanismo universal que casi nunca emerge a las plataformas de la discusión pública y frente al cual el hombre medio se encuentra absolutamente desamparado.

Cada uno de estos hechos: concentración de capitales, monopolización del poder, unificación de los medios de comunicación, crecimiento de la especialización, separación de la burocracia, usufructo de los sistemas militares, está en conflicto, contradice la exigencia social de la participación. Con frecuencia la oposición se plantea en términos de mutua exclusión. Las razones de Estado, la vigilancia y resguardo de los descubrimientos tecnológicos punta, la alta cualificación profesional en los niveles de gestión y 
decisión, etc., hacen cada vez más inviable la concurrencia participativa de amplias capas sociales que, al tiempo que son convocadas para una mayor intervención, son automáticamente excluidas de los centros en los que se decide su destino. Planteada la cuestión dialécticamente debería conducir al sistema social hacia una nueva síntesis política. No obstante, el paso a la nueva sociedad, puntualmente considerado, visto desde la óptica del tiempo presente, puede romperse en favor de cualquiera de las fuerzas contendientes. Esta amenaza pende sobre la actual situación histórica.

En otras épocas se daba por supuesto que el progreso de la razón y de la eticidad estaba regido por un principio que unificaba todas las manifestaciones. El hombre, mediante el ejercicio libre de la razón, caminaba automáticamente hacia la plenitud total como ser humano y ser social. Hoy podemos constatar que no es así. El desarrollo industrial, la tecnificación de la vida, lo que llamamos «sociedades altamente evolucionadas», promueven ciertas formas de racionalidad e inhiben otras. Incluso generan irracionalismos inevitables que hacen su aparición constante en la vida cotidiana y en muchos aspectos de la vida personal. Del mismo modo, inducen conductas responsables al tiempo que fomentan la irresponsabilidad y el egoísmo.

\section{LAS DIVERGENCIAS}

Existe una racionalidad de la producción. Se designa de esta forma a aquella en la que una serie de actividades y de procesos se encuentran organizados de manera que conducen a un fin previamente establecido. Cada elemento en esta serie de actividades recibe un valor funcional de colocación. Es la racionalidad que se atribuye a una fábrica o industria. Admitimos una optimización racional de la misma cuando el fin propuesto se alcanza con los medios más eficaces, con el menor costo y por el camino más corto. No importa que el fin sea racional en sí de acuerdo con unos criterios u otros. Lo que define este tipo de racionalidad es la organización de los medios y la disposición de los elementos. Se puede pretender conseguir un fin irracional de un modo totalmente racional. Lo que importa es que cada actividad tenga asignado un valor concreto de colocación en vistas a la meta que ha de alcanzarse.

Esta racionalidad está regida por dos principios:

1. Por la organización funcional para un fin.

2. Por la calculabilidad desde «el punto de vista de un espectador o de un tercero dispuesto a intervenir».

El tipo de racionalidad funcional que aquí se describe no es equivalente a la racionalidad en cuanto actos mentales realizados por un sujeto, ni hay entre ellas ninguna relación directa de derivación. Se puede decir que la racionalidad funcional de las actividades tiene que ser planteada mentalmente por alguien y que debe ser pensada durante su realización por quienes la llevan a cabo y, en consecuencia, la racionalidad funcional es un caso, un ejemplo, de la racionalidad mental. Sin embargo, no siempre sucede así.

«Si en la definición de la racionalidad funcional se carga el peso sobre esa organización para un fin, es funcionalmente irracional todo lo que destroza y trastorna esa ordenación funcional. Dicho trastorno puede no ser producido tan sólo por irracionalismo 
sustanciales, por sueños y explosiones de cólera de individuos no dominados, para citar los casos extremos, sino también por aquellas actos mentales que no se acomodan a la serie de actividades de que se trate» (Mannheim, 1958: 40).

Hay muchos casos concretos que nos pueden servir de ejemplo para comprobar el momento de la divergencia y separación de las dos formas de racionalidad. Supongamos la situación de un operario en una cadena de producción de cualquier proceso industrial. Todo ha sido diseñado con vistas a la obtención de unos objetos determinados que constituyen el fin inmediato de la serie de actos intermedios. Cada una de las ejecuciones ha sido calculada de modo que implican rutinizaciones fácilmente sustituibles. Al operario se le asignan unos actos susceptibles de ser llevados a cabo por cualquiera capaz de adquirir las destrezas requeridas. No se le pide que piense ni calcule su propia actividad, sino que la ejecute y rutinice. Una innovación superpuesta en forma de discursos propios, de imágenes, fantasías, alteraciones individualizadas, puede afectar gravemente a todo el sistema de fabricación. Una racionalización funcional implica, por tanto, una organización que discurre al margen de los actos de pensamiento, de las formas individuales de pensar. Al menos, inhiben todo aquello que no se ajusta íntegramente al proceso. La expresión «irracionalidad funcional», o «racionalidad funcional», no se utiliza para describir una acción en sí, sino únicamente una acción en cuanto referida o no a una finalidad previamente establecida y desde el conjunto de acciones que a ella se dirigen.

Desde este punto de vista hay que establecer la siguiente relación: «Cuando más ha progresado en una Sociedad la industrialización, así como la división del trabajo y organización que van estrechamente unidas a ella, tanto más hay esferas de la actividad humana que se hacen funcionalmente racionales, y con ello, calculables de antemano. Mientras que en Sociedades anteriores el individuo obraba de modo racional-funcional sólo ocasionalmente, en la Sociedad actual está obligado a obrar así cada vez en más sectores de su vida».

\section{AUTORRACIONALIZACIÓN}

El empleo de este término adquiere un sentido especial en las Sociedades industriales. Significa el control sistemático que el individuo ha de practicar sobre sus propios impulsos cuando tiene que proponerse de antemano el desarrollo de una actividad funcional-racional. Lo mismo ocurre cuando pretende insertarse en una estructura objetiva que tenga las mencionadas características de la funcionalidad. La regulación de la vida será muy distinta según el tipo de organización en el que se instale. Desde luego es básicamente diferente cuando la acción está fijada por los demás que cuando en cada momento debe hacer lo que ante él considere que es más pertinente. La autorracionalidad en un sistema organizacionista exige un entrenamiento encaminado al dominio y autocontrol no sólo del proceso de trabajo, sino también del grado de libertad, de la clase de pensamientos y del orden de sentimientos que están permitidos.

Si consideramos la racionalidad funcional como una forma de la racionalidad objetiva, vemos que ésta exige sólo unos actos de pensamiento y no otros, que, en la medida en que la racionalidad funcional está ejercida por unas determinadas personas, priva de la racionalidad personal a otras. Llevado hasta sus últimas consecuencias la distinción entre la racionalidad funcional y la racional personal, la racional «substancial» como la denomina Mannheim, y la autorracionalidad que aquella supone, deberíamos concluir 
que «la esencia de la racionalización funcional es eximir al individuo medio del pensamiento, de la inteligencia, de la responsabilidad y traspasar esas facultades a los individuos que dirigen la racionalización» (Id., 44-45).

Lo que se reclama de un individuo sometido a una actividad rigurosamente organizada, programada y calculada, es que elimine las opiniones y criterios que puedan distorsionar el proceso. El ideal es que asuma una mecanización, un automatismo de la conducta restringida al campo ocupacional en el que se mueve. El resto, todo cuanto prolifere internamente como mundo subjetivo y creador, deberá ser puesto entre paréntesis o visto como carga superflua de la existencia.

\section{LOS PELIGROS DE UNA RACIONALIDAD FUNCIONAL EXCLUSIVA}

La propensión dinámica de una sociedad que exhibe como valor supremo y modelo de desarrollo la racionalidad funcional conduce inevitablemente a la concentración de la organización en unos pocos sujetos. Sólo ellos tendrán la plena capacidad de decidir. Cuanto más compleja sea la organización y mayor el grado de especialización menor será el número de los que ostenten el control y el gobierno de su desenvolvimiento. Los organizadores serán los que desempeñen los puestos claves de la sociedad. La situación da lugar a la aparición de un núcleo poderoso, una élite separada de la masa de ciudadanos. La capacidad de juicio y la posibilidad de emitirlos sufre un desplazamiento. El hombre medio, el hombre de la calle verá mermadas sus zonas de influencia, y el cultivo de su propia inteligencia será cada vez menos necesario.

Estos hechos llevan consigo la sobrecarga de posiciones extremas. Cada implantación de nuevas racionalidades funcionales supone la renuncia a parcelas mayores de la propia inteligencia. Cada vez serán necesarios nuevos líderes, un nuevo tipo de organizadores que conduzcan la acción. Algunos de ellos pueden ser fabricados, demagógicamente improvisados, como una respuesta ad hoc a los vacíos que en la colectividad se van produciendo. $\mathrm{Y}$, en momentos de crisis, de cambios profundos, el individuo sentirá la angustia, el terror y el desamparo de no disponer de ninguna idea que le permita entender lo que va a ocurrir, porque los secretos y resortes mediante los que se rigen sus destinos están en otras manos. El gran ideal de la ilustración ha conducido a resultados contrarios de los que había pretendido alcanzar.

\section{LA RACIONALIDAD Y EL IMPACTO DE LOS IMPULSOS}

Desde esta perspectiva, estamos asistiendo por una parte a una tecnificación y racionalización sin precedentes de la sociedad, por otra, a una acumulación de seres humanos en grandes ciudades, en pequeños espacios físicos. Estas aglomeraciones exponen al individuo a las sugestiones y explosiones incontroladas de los impulsos, a comportamientos que han sido extensamente descritos por la Psicología de las multitudes y de la vida urbana. Es criterio general, confirmado por la experiencia histórica y por los reiterados fenómenos presentes, que, sometido el hombre a la presión de las grandes aglomeraciones, está expuesto a la brusca aparición de impulsos y «regresiones psíquicas» que no 
sufre cuando está aislado o «inserto orgánicamente en pequeñas asociaciones, y sostenido por ellas».

No siempre, hay que reconocer, desencadena la multitud conductas primarias e irracionales. Cuando la sociedad se articula en pequeños grupos orgánicos, los impulsos se canalizan a través de las finalidades que en ellos se proponen. Desempeñan la función de amortiguadores del impacto colectivo. Cuando este amplio tejido se destruye, el hombre queda a la intemperie, desprotegido frente al contagio emocional de una colectividad amorfa. El poder, el Estado, por otra parte, cae directamente sobre él sin que nada pueda resistir su control absoluto. Las sociedades antiguas desarrollaron múltiples sistemas de regulación. Sólo políticos despiadados, ignorantes o perversos, pueden ambicionar la destrucción del entramado social que cobija al ser humano. La ambición por conseguir una máxima disponibilidad lleva consigo peligros de involución cuyas consecuencias son imprevisibles.

No es el impulso, el sentimiento espontáneo, las tendencias inmediatas, pese a su irracionalidad, lo que constituye un peligro, ni lo que es pernicioso. Su presencia es necesaria en ocasiones para alcanzar fines objetivos y valiosos, para llevar a cabo empresas heroicas, para actos de entrega y dedicación. También tiene sentido como expresión de pura vitalidad, de simple goce de existir. La perturbación surge cuando todo este extenso territorio de la vida queda a la intemperie, sin destino, como una fuerza errante y sin canales por los que discurrir, o cuando se convierte en la forma básica de la actuación política, como plataforma de la dinámica social.

Cuando en nuestra sociedad descubrimos embolsamientos de irracionalidad que funcionan como vertederos de residuos que van adquiriendo dimensiones colosales, entonces descubrimos que la Sociedad Industrial, la racionalidad funcional, ha dejado sin racionalizar su propia estructura orgánica. En estas circunstancias el empleo de la violencia se convierte en el instrumento cotidiano a través del cual se satisfacen todos aquellos impulsos almacenados y descontrolados. Nuestra sociedad se asienta sobre un volcán a punto de estallar.

«La gran ordenación -escribía Mannheim interpretando esta situación- y organización, creciente en términos aterradores como la del orden del trabajo de nuestra Sociedad moderna, se encuentra colocada en un medio de larvado empleo de la violencia. Nunca podrá saberse cuándo y cómo aparecerá la decisión sangrienta, en lugar de la distribución pacífica de funciones en la esfera de la política exterior, o de compulsar las fuerzas en el interior. Esa irracionalidad no aplicada, presente siempre en la estructura objetiva de nuestro mundo social, es la que moviliza de vez en vez los instintos de los grupos de hombre-masa. Los mismos hombres que en su esfera de trabajo, en la esfera de la división y organización del trabajo, se encuentran tan racionalizados, pueden transformarse en todo momento en destructores de máquinas y guerreros sin escrúpulos» (Id., 51).

\section{LAS FORMAS DE MORALIDAD}

La misma duplicidad que aparece en la racionalidad, coexistiendo una racionalidad funcional con una extensa irracionalidad personal, «substancial», puede observarse en el orden de la moralidad. 
La sociedad industrial exige un elevado sentido de la responsabilidad, pero, paralelamente, fomenta zonas de irresponsabilidad. La moralidad funcional consiste en un conjunto de normas que regulan el obrar y con cuya eficacia se garantiza el desenvolvimiento social y la práctica operativa de las distintas capas ocupacionales. La moralidad substancial se caracteriza por contenidos concretos que afectan a los sentimientos íntimos, a las creencias y convicciones individuales o grupales. A medida que progresa la racionalidad funcional en la sociedad industrial más tiende a «neutralizar la moralidad substancial» y a retrotraerla al campo de lo exclusivamente privado.

Dentro de la moralidad funcional se han distinguido varias etapas históricas, que representan modalidades diferentes y distintas repercusiones sobre la moralidad personal:

1. La moralidad en el estado de la horda

2. La moralidad en el estado de «competencia individual»

3. La moralidad en el estado de «solidaridad de grupo transindividual»

En la primera, el individuo no ha adquirido todavía una conciencia y responsabilidad propia. En la segunda, el ser humano va conquistando su individualidad y se siente capaz de ver el mundo de distinta manera a como le ha sido dado por la tradición o por los criterios grupales. Se percibe a sí mismo como protagonista de una responsabilidad individual mediante la que domina y decide su propio destino. En la tercera, el hombre se ve obligado a renunciar a parte de sus intereses individuales subordinándolos a los grandes intereses del grupo. Los empresarios unen sus capitales para crear organizaciones industriales que puedan competir en el mercado. Surgen asociaciones obreras para coordinar cooperativamente los propios intereses. Esta solidaridad ya no es mecánica, como la de la horda, sino reflexiva, calculadora y racionalmente asumida. Renuncia a beneficios parciales y a la competencia individual. Autolimita sus propios derechos en bien del todo del que forma parte. Surge así una ratio social de la moralidad en la que el hombre se acostumbra a calibrar y planificar cada vez zonas más extensas de la vida. Los peligros, no obstante, son los mismos que los de la racionalidad funcional. El control de la conducta se transfiere a los responsables de la organización. A medida que crece la centralización de las decisiones y la normativización especializada disminuye la responsabilidad personal y deja en suspenso la ética individual. Hoy, sobre todo, el monopolio y la enorme implantación de los medios de comunicación puede usurpar la responsabilidad de enjuiciar los hechos y tomar una posición ética frente a los mismos. Porque son los medios los que indican qué son los hechos y la reacción que ante ellos se debe adoptar. El resultado es, en ocasiones, un tipo de hombre fuertemente moralizado en determinados campos de actividad, pero carente de una ética que le permita organizar ninguna escala de valores.

La paradoja de las situaciones propuestas estriba en que, realmente, la racionalidad y moralidad funcional son una conquista, un logro de la humanidad al que es imposible renunciar. Ninguna sociedad moderna puede prescindir de ellas sin autodestruirse. El abastecimiento técnico y la satisfacción de las necesidades básicas de sociedades cuantitativamente inmensas como son las sociedades actuales no pueden mantenerse sin una fuerte racionalización de todos los medios de producción. Pero este proceso, según la manera de llevarlo a cabo, desencadena la retracción de otras dimensiones de la racionalidad y ủe la eticidad imprescindible para el ser humano. Lo que de momento evidencian estas situaciones es que una forma de racionalidad no implica necesariamente el progre- 
so de toda forma de racionalidad. Y esto supone el problema de una reorganización social.

Naturalmente, hay otras cuestiones no abordadas y que nos llevarían a temas más inquietantes. No pueden introducirse falsificaciones en el interior de la racionalidad funcional? Son idénticas todas las formas de racionalidad funcional? No evoluciona la racionalidad funcional a posiciones que incorporan una fragmentación y rotura de su estructura interna? Existen racionalidades cuyo soporte afecta a la racionalidad misma?

Jean F. Lyotard planteaba alguna de estas cuestiones en La condición postmoderna. Las nuevas tecnologías, los juegos del lenguaje, la paralogía están alternando todas las posiciones clásicas. Incluso el saber está cambiando de signo. «El antiguo principio, escribe, de que la adquisición del saber es indisociable de la formación (Bildung) del espíritu, e incluso de la persona, cae y caerá todavía más en desuso. Esa relación de los proveedores y de los usuarios del conocimiento con el saber tiende y tenderá cada vez más a revestir la forma que los productores y los consumidores de mercancías mantienen con estas últimas, es decir, la forma valor. El saber es y será producido para ser vendido, y es y será consumido para ser valorado en una nueva producción: en los dos casos, para ser cambiado. Deja de ser en sí mismo su propio fin, pierde su «valor de uso». (Lyotard, 1984: 16)».

Las conclusiones confirman lateralmente las paradojas anteriormente descritas, pero ofrecen matices que, exigirían un replanteamiento de la racionalidad funcional de modo que incorpore el impacto de las nuevas tecnologías.

\section{EL PROBLEMA EDUCATIVO}

Racionalidad especulativa (Parménides), racionalidad científica (Kant, Ilustración), racionalidad funcional (Mannheim), son algunas de las formas bajo las que la racionalidad se ha expresado. Su presencia histórica ha sido propuesta desde la perspectiva de un autor determinado. En realidad, corresponden a grupos de pensadores cuyos sistemas perviven en la actualidad. Con ello, a pesar de todo, se inicia lo que debería ser un minucioso desarrollo en torno a la verdadera naturaleza de las mismas. Con estas formas, por otra parte, no se agotan las que la racionalidad puede adquirir, ni las que ha adquirido de hecho. De momento, sin embargo, nos permiten extraer algunas conclusiones que afectan a las ciencias de la educación y a las prácticas de enseñanza.

En primer lugar, cada una de ellas se manifiesta como una forma relativamente exclusiva y excluyente de otras formas reales. La racionalidad especulativa de Parménides se formula como la única vía de acceso a la verdad y a la justicia. La razón se rige por reglas que ella se da a sí misma. El ser se reduce a lo que esa racionalidad determina y pone. A su vez, la racionalidad científica kantiana debilita la racionalidad especulativa y obliga a desarrollar otras formas de saber, como es el saber «práctico», que no puede ser incluido en ninguna de las formas anteriores. La racionalidad científica se rige por reglas de «conocimiento objetivo» y se convierte en medida de la realidad y del conocer. La racionalidad funcional gobierna el sistema de producción y está sometida a los criterios de eficacia y de calculabilidad. Impone el orden del obrar, de lo que se fabrica y de lo que debe ser obtenido. 
En segundo lugar, no es posible derivar unas formas de la racionalidad de otras. Más bien, tal como han sido defendidas, cada una tiende a eliminar o a reducir a las demás. La racionalidad funcional, por ejemplo, tiende a transformar la racionalidad científica en materia apta para el propio ejercicio funcional. Es decir, a despojarla de su propia naturaleza. Incluso podemos dar un paso adelante: De los principios internos de cada una de las racionalidades no se pueden extraer los demás. Estos principios son distintos e irreductibles entre sí.

En tercer lugar, una forma de racionalidad imperante, global, lleva consigo un prototipo de saber. De esta forma, en el ámbito de las ciencias de la educación, una racionalidad especulativa implica una pedagogía especulativa. Y una racionalidad funcional implica una pedagogía funcional. Pero, además, cada racionalidad arrastra consigo un sistema social y un sistema educativo. La racionalidad especulativa encontró su máximo exponente político y educativo en la construcción platónica. La racionalidad científica lo tuvo en los enciclopedistas y en su lucha por una comunidad universal.

El problema educativo, sin embargo, en sus aspectos puntuales más destacados, surge cuando aparecen formas hegemónicas de racionalidad del tipo de la racionalidad funcional, o de otras clases afines, como ocurre con la racionalidad formal de Max Weber. Porque estas racionalidades no incluyen la totalidad del sujeto gnoseológico, ni la del sujeto psíquico, ni el sujeto personal como elemento de su propio devenir. En la racionalidad especulativa y científica se produce una integración. El sujeto está inmerso en las categorías que definen la especulación o la cientificidad. Allí encuentra el sujeto su propia objetividad y, en consecuencia, su progreso. Pero la racionalidad funcional lo centrifuga y rechaza de su centro de atracción. Lo expulsa hacia fuera, lo separa de su órbita de acción. Mientras tanto, la educación es imposible sin una participación directa, constante del sujeto gnoseológico y personal. La educación, en consecuencia, no mantiene las mismas relaciones con todas las formas de la racionalidad. Aquí radica uno de los mayores problemas y retos educativos. De un lado, la educación no puede renunciar a las formas de racionalidad que el hombre ha conquistado y a través de las cuales ha construido el mundo en el que vive. De otro, tendrá que integrarlas de forma que sus propias tendencias no lleguen a aniquilarse entre sí. Y, finalmente, tendrá que recoger en su seno aquello que algunas formas racionales eliminan y sin lo cual la educación misma es imposible.

Todo ello constituye un conjunto de problemas que deberán ser vistos uno a uno con más detenimiento. En cualquier caso, ninguna solución simple será ya posible.

\section{REFERENCIAS BIBLIOGRÁFICAS}

Beaufret, J. (1955). Le Poème de Parménide, PUF, París.

BREZINKA, W. (1990). Conceptos básicos de la ciencia de la educación, Herder, Barcelona.

Bueno, G. (1974). La metafísica presocrática, Pentalfa, Oviedo.

ELSTER, J. (1990). El cambio tecnológico. Investigaciones sobre la racionalidad y la transformación social, Gedisa, Barcelona.

FARRINGTON, B. (1973). Ciencia y política en el mundo antiguo, Ayuso, Madrid. 
Foucault, M. (1986). «Por qué hay que estudiar el poder: La cuestión del sujeto», en Varios: Materiales de sociología crítica, La Piqueta, Madrid.

Habermas, J. (1986). Ciencia y Técnica como «ideología», Tecnos, Madrid.

HABERMAS, J. (1981). Historia y crítica de la opinión pública, Gustavo Gili, Barcelona.

HABERMAS, J. (1981). Theorie des kommunikativen Handelns, Suhrkamp, Frankfurt.

JAEGER, W. (1977). La teología de los primeros filósofos griegos, F. de C.E., México.

JASPERS, K. (1957). La razón y sus enemigos en nuestro tiempo, Ed. Sudamericana, Buenos Aires.

KANT, I. (1960). Crítica de la razón pura, Librería General de Victoriano Suárez, Madrid.

KANT, I. (1988). Respuesta a la pregunta: ¿Qué es la Ilustración?, Tecnos, Madrid.

LYOTARD, J. F. (1984). La condición postmoderna, Cátedra, Madrid.

Maestro, A. y Romagosa, J. (1988). ¿Qué es la Ilustración?, Tecnos, Madrid.

MANNHEIM, K. (1958). El hombre y la sociedad en la época de crisis, Leviatán, Buenos Aires.

MANNHEIM, K. (1973). Ideología y utopía, Aguilar, Madrid.

MENDELSSOHN, M. (1988). «Acerca de la pregunta: ¿A qué se llama ilustrar?», en Maestro, A. y R., O.C., Tecnos, Madrid.

PARMENIDES (1983). Sobre la naturaleza, Orbis, Barcelona.

PAGELS, H. (1991). Los sueños de la razón, Gedisa, Barcelona.

PIEBE, A. (1971). ¿Qué es verdaderamente la Ilustración?, Doncel, Madrid.

SPROTT, W J. H. y YounG, K. (1967). La muchedumbre y el auditorio, Paidós, Buenos Aires. WHITEHEAD, A. N. (1985). La función de la razón, Tecnos, Madrid. 